Received 16 November 2021 Accepted 27 December 2021

Link to DOI:

10.25220/WNJ.V05.S2.0003

Journal Website: www.worldnutrijournal.org

\title{
Nutritional opportunity and brain development among fetus and infant
}

Setyo Handryastuti ${ }^{1}$, Ni Ketut Susila Dharma Asih ${ }^{2}$

1. Child Health Department, Faculty of Medicine, Universitas Indonesia

2. Danone Specialized Nutrition Indonesia

\begin{abstract}
The right for optimal cognitive, social, and emotional behavioral development is fundamental for every child. The cognitive, social, and emotional parts of the brain continue to develop across the lifespan. An immense portion of the brain's structure and capacity is shaped early in life. Nevertheless, a cautious approach must be undertaken to ensure optimal development with longterm consequences during this sensitive period. Among the identified factors for optimal brain development, provision of optimal nutrition shared its portion as one of the fundamentals. This article will review the essential features of nutrients in the fetal, postnatal, and infancy period in relation to brain development.
\end{abstract}

Keywords brain development, cognitive, nutrient, nutrition

\section{Introduction}

The brain, arguably one of the essential organs in the body, requires a high level of nutrition to grow and function optimally. In fact, the brain utilizes $60 \%$ of the total intake in the body. To ensure that the neural substrates are incorporated during development, proper maternal and infant nutrition is needed. It is important to note that each nutrient has its period (sensitive period) and their deficiency, subsequently, can cause a detrimental effect on brain development. ${ }^{1,2}$

The early years of life are fundamental for children's development of foundational cognitive and socioemotional characteristics. Globally, onethird of children failed to reach their developmental potential by pre-school age. In areas of the world where risk factors, such as infection, malnutrition, poverty, and lack of availability to high-quality healthcare and educational services were still

\section{Corresponding author:}

Ni Ketut Asih Susila Dharma Asih

Medical and Sciences Affair

Danone Specialized Nutrition Indonesia

Email:ni-ketut.asih@danone.com present, low development scores were expected. ${ }^{3}$ For better development, several of these risk factors can be alleviated through proper nutrition.

Several nutrients that have been studied with respect to nutrition and brain development are folate, iodine, iron, vitamin D, choline, and docosahexaenoic acid (DHA), to name a few. In this review scope, the authors will focus mainly on the six nutrients listed above with the aim to review recent literature regarding the evidence for a health benefit of nutrition in the development of the brain in infants.

\section{Physiological brain development}

Brain development is a protracted process that begins about two weeks after conception and continues into young adulthood 20 years later. Prenatal brain growth is primarily under genetic and environmental control (i.e., folic acid), all of which can affect the developing brain. In contrast, much of brain development that occurs postnatally is experience-dependent and characterized by geneenvironment interactions. ${ }^{4}$ 


\section{Neurulation}

After forming a three-layered, spherical structure from a developing embryo, the cells thicken to form a neural plate, followed by forming a neural tube. The neural tube becomes a three-vesicle structure after completion and briefly a five-vesicle structure. The anterior portion of the tube will become the forebrain, the diencephalon, and the basal ganglia. The cells around the middle vesicle will become the midbrain, connecting the diencephalon to the hindbrain. The hindbrain, which consists of the medulla oblongata, the pons, and the cerebellum, will emerge from the tube's back end. ${ }^{4,5}$

\section{Proliferation}

Once the general structure of the neural tube has been set out, the cells that line the innermost part of the tube (ventricular zone) proliferate at a logarithmic rate. A second zone (marginal zone) forms as these cells multiply, containing axons and dendrites. This stage lasts a long time, yielding in a newborn brain with far more neurons than an adult brain. The overproduction of neurons is gradually balanced out by the process of apoptosis (or programmed cell death). ${ }^{4}$

\section{Cell migration}

After the cells are born, they migrate to their final destinations. The cerebral cortex is composed of multilayered tissue several millimeters thick, formed by the movement of cells in an inside-out direction (radial migration). This movement begins in the ventricular zone and migrates through the intermediate zone, with the cells eventually reaching their final destination outside the developing brain. ${ }^{4}$

\section{Differentiation}

When a neuron reaches its destination, it can either differentiate into a mature neuron with axons and dendrites, or it can be retracted by apoptosis. The development of axons is facilitated by growth cones, tiny structures that emerge at the edge of an axon. Molecular guidance signals and anatomic structures drive the cellular processes that occur at the growth cone promoting growth toward specific targets and away from others. Dendrite formation occurs by a slightly different path, which is thought to be influenced by genes that control the calciumregulated transcription factors. ${ }^{4}$

\section{Synaptogenesis}

In general, synapse, the point of contact between two brain cells (i.e., two neurons and frequently a dendrite and an axon), is first seen about the 23rd week of pregnancy, with peak development lasting the first year of life. Similar to the concept of neurons, massive overproduction of synapses is accompanied by a gradual reduction or pruning. It is worth noting that the different structures of the brain reach their peak of synapse output at different times (i.e., visual cortex peak between the 4th and 8th postnatal month, while prefrontal cortex until the 15 th postnatal month). The difference in timing in peak synapse production is crucial because it affects the timing of the plasticity of these regions, with later peak synapse production leading to longer plasticity of the region. ${ }^{4}$

\section{Synapse pruning}

Following the overproduction of synapses, pruning of the unused and overabundance of the synapses usually ensued. The stages of brain development are mostly gene-mediated before synaptogenesis, yet, after the synapses are eliminated, the balance changes to pruning, which is primarily experiencedriven. The timing of synapse pruning, like synaptogenesis, is dependent on the region of the brain where it occurs. Around the fourth and sixth years of life, pruning in areas of the cortex involved in visual and auditory perception is completed, whereas pruning in areas involved in higher cognitive functions continues through adolescence. ${ }^{4}$

\section{Myelination}

Myelination is the final step in the brain's growth. In this process, the axons of neurons are wrapped in fatty cells, ultimately facilitating neuronal activity and communication. Myelination takes place in a different region of the brain at different times. Regions of the brain in certain sensory and motor areas are myelinated earlier in a process completed 
around the preschool age. In comparison, in regions involved in higher cognitive abilities (i.e., prefrontal cortex), the process is not complete until adolescence or early adulthood. ${ }^{4}$

\section{Brain development and early nutrition effects}

The vulnerability of a developing brain process, region, or circuit in the aspect of early life nutrition is determined by two factors: the timing of the nutrition deficiency and the region's requirement for that nutrient at that time. For example, In the pediatric population, the risk of iron deficiency varies, peaking during the fetal/newborn period, 624 months of age, and during the adolescent years in menstruating females. ${ }^{6}$ Table 1 summarized the critical process influenced by particular nutrients during neurodevelopment, while Table 2 summarized the examples of natural sources of nutrients.

Table 1. Critical processes during neurodevelopment affected by specific nutrients ${ }^{6}$

\begin{tabular}{|c|c|c|c|c|}
\hline $\begin{array}{l}\text { Neurologic } \\
\text { process }\end{array}$ & Cell type & Function & Nutrient example & $\begin{array}{l}\text { At risk during } \\
\text { late gestation and } \\
0-3 \text { years }\end{array}$ \\
\hline \multicolumn{5}{|l|}{ Anatomy } \\
\hline & Neuron & $\begin{array}{l}\begin{array}{l}\text { Division } \\
\text { (neurogenesis) }\end{array} \\
\text { Migration } \\
\text { Differentiation } \\
\text { (Neurite } \\
\text { outgrowth; } \\
\text { synaptogenesis) }\end{array}$ & $\begin{array}{l}\text { Protein, } \\
\text { carbohydrates, iron, } \\
\text { copper, zinc, LC- } \\
\text { PUFA, iodine, } \\
\text { vitamin A, vitamin } \\
\text { B6, vitamin D, } \\
\text { vitamin C }\end{array}$ & $\begin{array}{l}\text { Global, } \\
\text { hippocampus, } \\
\text { striatum, cortex, } \\
\text { retina }\end{array}$ \\
\hline & Oligodendrocyte & Myelination & $\begin{array}{l}\text { Protein, } \\
\text { carbohydrates, iron, } \\
\text { iodine, selenium, } \\
\text { zinc, vitamin B6, } \\
\text { vitamin B12 }\end{array}$ & Global \\
\hline \multicolumn{5}{|l|}{ Chemistry } \\
\hline & Neuron astrocyte & $\begin{array}{l}\text { Neurotransmitter } \\
\text { concentration, } \\
\text { receptor, reuptake }\end{array}$ & $\begin{array}{l}\text { Protein, iron, iodine, } \\
\text { copper, zinc, } \\
\text { selenium, choline, } \\
\text { vitamin B6, vitamin } \\
\text { D }\end{array}$ & $\begin{array}{l}\text { Global, } \\
\text { hippocampus, } \\
\text { nucleus } \\
\text { accumbens, } \\
\text { VTA, cortex, } \\
\text { cerebellum }\end{array}$ \\
\hline \multicolumn{5}{|c|}{ Physiology \& Metabolism } \\
\hline & $\begin{array}{l}\text { Neuron } \\
\text { oligodendrocyte }\end{array}$ & $\begin{array}{l}\text { Electrical } \\
\text { efficiency }\end{array}$ & $\begin{array}{l}\text { Glucose, protein, } \\
\text { iron, iodine, zinc, } \\
\text { choline, copper }\end{array}$ & Global \\
\hline
\end{tabular}


Table 2. Examples of natural sources of selected nutrients ${ }^{2}$

\begin{tabular}{|c|c|}
\hline Nutrient & Examples of sources \\
\hline \multirow[t]{6}{*}{ Folate } & Dark leafy greens \\
\hline & Legumes \\
\hline & Dairy products \\
\hline & Grains \\
\hline & Poultry \\
\hline & Eggs \\
\hline \multirow[t]{6}{*}{ Iodine } & Seaweed \\
\hline & Seafood \\
\hline & Oysters \\
\hline & Legumes \\
\hline & Strawberries \\
\hline & Iodized salt \\
\hline \multirow[t]{5}{*}{ Iron } & Red meat \\
\hline & Spinach \\
\hline & Liver \\
\hline & Shellfish \\
\hline & Legumes \\
\hline \multirow[t]{5}{*}{ Vitamin D } & Sunshine \\
\hline & Fatty fish \\
\hline & Beef liver \\
\hline & Egg yolks \\
\hline & Mushrooms \\
\hline \multirow[t]{5}{*}{ Choline } & Eggs \\
\hline & Red meat \\
\hline & Liver \\
\hline & Peanuts \\
\hline & Dark leafy greens \\
\hline \multirow[t]{4}{*}{ Docosahexaenoic acid } & Free-range eggs \\
\hline & Grass-fed beef \\
\hline & Fatty fish \\
\hline & Algae \\
\hline
\end{tabular}




\section{Nutrients}

\section{Folate}

Folate is one of the recognized nutrients to support normal metabolic, physiological, and neuronal functions and is involved in methylation reactions, nucleotides synthesis, neurotransmitters and myelin, and homocysteine regulation at non-toxic levels. ${ }^{7}$ Neural tube defects (ranging from anencephaly to asymptomatic closed spinal lesions), which affect 1 in 10,000 pregnancies in Europe, have been associated with low intake of folate during pregnancy. ${ }^{8}$ Based on emerging evidence, folate is now recommended as a necessary nutrient from before conception to later pregnancy.

Myelination of the brain, which occurs at its peak between mid-gestation and the second year of life, is critical for cognitive development. It protects nerve axons and facilitates communication between neurons and may be especially vulnerable to folate deficiency. ${ }^{9}$ According to a recent study, folic acid supplementation in the second and third trimester of pregnancy, as recommended in the first trimester, can affect children's cognitive ability and brain function as young as 11 years of age. ${ }^{10}$

\section{Iodine}

Iodine is an essential micronutrient required in human diets. The thyroid hormone's effect on brain growth is mediated by iodine, an essential component of the hormone. This micronutrient also maintains the redox balance. Thyroid hormone also influences processes, such as myelination, cell migration and differentiation, synaptogenesis, dendrite structure, transcriptional regulation, and synaptic plasticity. ${ }^{11,12}$

Synaptic plasticity, along with long-term potentiation, is one of the processes that sustain learning and memory. Synaptic plasticity works by altering the amount of neurotransmitter release or the number of receptors on the postsynaptic cell. ${ }^{13}$ Thyroid hormone is thought to play a role in neurotransmitter release throughout fetal development and may even act as neurotransmitters themselves, implying that iodine is needed. Thyroid hormones have also been shown to promote neuronal contact by interacting with other neurotransmitter types such as acetylcholine, norepinephrine, and dopamine. ${ }^{11}$

Iodine deficiency affects all age groups, and a lack of iodine may trigger hypothyroidism and other disorders, classified as iodine deficiency disorders (IDDs). Iodine deficiency can lead to oxidative stress, which can disrupt the function of trophoblastic cells and the placental vascular net. Behavioral abnormalities range from global abnormalities in severe deficiency to more inferior learning and memory, sensory gating, and in milder deficiency, increased anxiety. ${ }^{11,}{ }^{14}$ Iodine supplementation may be recommended to meet individual needs, especially for expectant mothers, in order to prevent potential negative impacts and optimize fetal growth.

\section{Iron}

Iron, a structurally essential component of hemoglobin and one of the micronutrients that influences early brain development, has been extensively researched. ${ }^{15}$ Iron deficiency is the most common nutritional problem worldwide. Prenatal and early childhood iron deficiency can result in permanent neural issues. ${ }^{16}$ Fetal iron sufficiency supports neural energy metabolism, the dendrites and synapses development, neurotransmitters synthesis, and the onset of myelination. ${ }^{17}$ In an irondeficient fetus, brain development does not undergo a typical trajectory and the suboptimal outcomes are almost certainly irreversible even when the iron is replete. $^{2}$

Iron deficiency in the first 30 weeks of pregnancy was linked to a higher prevalence of autism spectrum disorder, attention deficit hyperactivity disorder (ADHD), and intellectual disability in children compared to children whose mothers were diagnosed later in pregnancy or were not diagnosed at all, according to a study involving over half a million of children in Sweden. ${ }^{18}$ Along with that, iron deficiency anemia during later childhood has been linked to poor cognition and school achievement and in a longitudinal study among adolescents with iron deficiency anemia in childhood continued to score lower in intelligence quotient (IQ), social problems, and inattention compared to non-anemic peers. ${ }^{9}$ 


\section{Vitamin D}

Vitamin D, a lipid-soluble vitamin synthesized in our skin when we are exposed to sunlight. This vitamin has long been recognized for its function in calcium homeostasis and maintaining bone integrity. Vitamin D is essential for neuronal development in the early stages of life. Vitamin D is a neuroactive steroid and vitamin $\mathrm{D}$ receptors have also been found in the human brain. ${ }^{19}$ Vitamin D plays a role in neuronal proliferation, differentiation, neurotransmission, neuroplasticity, neuroprotection, and myelination, according to data from in vitro, ex vivo, and animal models. ${ }^{20}$ This is further reinforced by the fact that vitamin $\mathrm{D}$ levels are linked to the levels of many neurotrophic factors, including nerve growth factors (NGFs) and those of neurotrophins, both of which are essential for the maintenance and the growth of neurons. ${ }^{21}$

With the advancement of research, vitamin D has been related to cognitive dysfunction, psychosis, and autism in the interchange of decreased vitamin D levels. In a study of mothers and offspring with vitamin D deficiency, listening, memory disorders, and grooming habits were found to be impaired in early childhood. In specific, vitamin D deficiency in the first trimester of pregnancy predicted worse performance in cognitive and language skills, while during the third trimester, this deficiency affected motor development. ${ }^{20}$ According to a recent study on the effect of vitamin D supplementation in the treatment of children with autism spectrum disorders, oxidative stress and mitochondrial dysfunction are common in individuals with autism spectrum disorders, and vitamin D acts as a counterprotective mechanism by protecting the genome from oxidative stress and DNA damage and the regulation of cellular proliferation and differentiation. ${ }^{22}$

\section{Choline}

Chemically, choline is closely related to the Bvitamin family. Choline is a precursor that aids in the biosynthesis of a metabolite important for fetal development, especially in the brain. The synthesis of acetylcholine, a neurotransmitter fundamental for synaptogenesis and leukocyte function, also requires enough choline. The downstream metabolites betaine, dimethylglycine, and sarcosine are methyl donors for the regeneration of methionine from homocysteine. ${ }^{23,24}$ Choline is stored in the brain as membrane-bound phospholipids that are hydrolyzed by choline acetyltransferase to yield choline for acetylcholine synthesis, and it passes through the blood-brain barrier through facilitated diffusion regulated by the choline concentration gradient. ${ }^{24}$

Between the 10th week of pregnancy and two years of age, brain phospholipids are thought to increase twofold and threefold in the cortex and white matter, respectively. ${ }^{23}$ Choline is also a critical component of membrane synthesis and methylation in fetal hippocampus neural progenitor cells (starter cells). At particular times during fetal development, these cells divide, migrate, proliferate, and undergo apoptosis. ${ }^{23,} 24$ A recent analysis of neonatal brain metabolite concentrations using magnetic resonance imaging (MRI) scanning discovered that the advancing concentrations of choline were agerelated, which are likely to reflect an increased cell membrane synthesis or turnover rate. ${ }^{25}$

Choline production is boosted by increased estrogen production. While there is a possible increased capacity for the body to synthesize choline during pregnancy, evidence from animal models indicated that fetal and infant demand is so high that maternal stores are exhausted during pregnancy and lactation. Low maternal choline intake has been linked to an increased risk of both neural tube defects and cleft palates during pregnancy. ${ }^{26}$

\section{Docosahexaenoic acid}

Long-chain polyunsaturated fatty acids (LC-PUFA), including docosahexaenoic acid (DHA) together with arachidonic acid (AA), are incorporated into membrane phospholipids and are active activators of many gene transcription factors (e.g., peroxisome proliferator activated receptors). ${ }^{27}$ The critical role of n-3 LC-PUFA is generally contributed to incorporating DHA in uniquely high levels in the central nervous system. ${ }^{28,29}$ DHA accumulates in the brain throughout the intrauterine and neonatal periods, up to the age of two years, and the high levels of DHA in the brain are maintained throughout life. ${ }^{27}$

The rate of membrane DHA incorporation in early life is determined by maternal transfer, dietary 
supply, and endogenous LC-PUFA production due to lack of de novo PUFA synthesis. Non-esterified PUFA derived primarily from the maternal circulation is transferred through the placenta to provide intrauterine PUFA. LC-PUFA accumulation in the fetus occurs mainly in the third trimester, starting about the 30th week of pregnancy when weight gain becomes more rapid and growth is followed by fat tissue deposition. Nonetheless, as opposed to the high relative concentrations of LCPUFAs deposited in the brain, fetal fat tissues contain comparatively low levels of DHA and AA. The maternal transfer of PUFA by breastmilk supports the postnatal accumulation of LC-PUFA in infant tissue, and blood levels of LC-PUFA in breast-fed infants remain higher than maternal levels for some time postnatally. ${ }^{27}$

The formation of neurons is complete at prenatal stages, yet, gliogenesis (the development of astrocytes, oligodendrocytes, and microglial cells) is not completed until after birth. Low DHA availability can affect neurotransmitters such as acetylcholine, dopamine, serotonin, norepinephrine, glutamate, and gamma-aminobutyric acid (GABA). During synaptogenesis, DHA is incorporated into nerve growth cones and synaptosomes, implying that the mother's DHA intake must be adequate for this process to occur at optimal levels. Deficient/lower levels of long-chain omega-3s or DHA were found among children with ADHD, dyspraxia or developmental coordination disorder, autistic spectrum disorder, and mood disorder. ${ }^{30}$

\section{Conclusion}

Optimal brain growth and maintenance requires a prime environment, internally and externally, one of them is adequate nutrition. Timing, dose, and duration of nutrient intake are crucial, e.g., folate during the fetal period, while choline and DHA in postnatal and infantile period. Synergistic interaction between nutrients should be considered in the development of an optimal brain. Sensitive periods for action undertaken and care must be sought to avoid profound and irreversible sequelae of nutrient deficiency.

\section{Conflict of Interest}

Authors declared no conflict of interest regarding this article.

\section{Open Access}

This article is distributed under the terms of the Creative Commons Attribution 4.0 International Licence

(http://creativecommons.org/licenses/by/4.0/), which permits unrestricted use, distribution, and reproduction in any medium, provided you give appropriate credit to the original author(s) and the source, provide a link to the Creative Commons license, and indicate if changes were made.

\section{References}

1. Cheatham CL, Sesma HW, Bauer PJ, Georgieff M. The development of declarative memory in infants born preterm. Adv Child Dev Behav. 2010; 38: 111-35.

2. Cheatham CL. Nutritional factors in fetal and infant brain development. Ann Nutr Metab. 2019; 75 (suppl 1): 20-32.

3. McCoy DC, Peet ED, Ezzati M, Danaei G, Black MM, Sudfeld CR, et al. Early childhood developmental status in low- and middle-income countries: National, regional, and global prevalence estimates using predictive modeling. PLoS Med. 2016; 13(6): e1002034.

4. Tierney AL, Nelson CA. Brain development and the role of experience in the early years. Zero Three. 2009; 30(2): 9-13.

5. Nikolopoulou E, Galea GL, Rolo A, Greene NDE, Copp AJ. Neural tube closure: cellular, molecular and biomechanical mechanisms. Development. 2017; 144(4): 552-66.

6. Cusick SE, Georgieff MK. The role of nutrition in brain development: The golden opportunity of the "first 1000 days". J Pediatr. 2016; 175: 16-21.

7. Cosín-Tomás M, Luan Y, Leclerc D, Malysheva OV, Lauzon N, Bahous RH, et al. Moderate folic acid supplementation in pregnant mice results in behavioral alterations in offspring with sex-specific changes in methyl metabolism. Nutrients. 2020; 12(6): 1716.

8. European Commission. EU Science Hub, European Platform on Rare disease Restriction, EUROCAT DATA, EUROCAT, Prevalence per 10,000 Births. Neural Tube Defects, 2006 to 2016. All Full Registries. Available online: https://eu-rdplatform.jrc.ec.europa.eu/eurocat/eurocatdata/prevalence (accessed on 30 April 2021).

9. Prado EL, Dewey KG. Nutrition and brain development in early life. Nutr Rev. 2014; 72(4): 267-84.

10. Caffrey A, McNulty H, Rollins M, Prasad G, Gaur P, Talcott JB, et al. Effects of maternal folic acid supplementation during the second and third trimesters 
of pregnancy on neurocognitive development in the child: an 11-year follow-up from a randomised controlled trial. BMC Med. 2021; 19(1): 73.

11. Redman K, Ruffman T, Fitzgerald P, Skeaff S. Iodine deficiency and the brain: Effects and mechanisms. Crit Rev Food Sci Nutr. 2016; 56(16): 2695-713.

12. Farias PM, Marcelino G, Santana LF, de Almeida EB, Guimarães RdCA, Pott A, et al. Minerals in pregnancy and their impact on child growth and development. Molecules. 2020; 25: 5630.

13. Drever BD, Riedel G, Platt B. The cholinergic system and hippocampal plasticity. Behav Brain Res. 2011; 221: 505-14.

14. Navarro D, Alvarado M, Navarrete F, Giner M, Obregon MJ, Manzanares I, et al. Gestational and early postnatal hypothyroidism alters VGLuT1 and VGAT bouton distribution in the neocortex and hippocampus, and behavior in rats. Front Neuroanat. 2016; 17: 9.9

15. Guzmán Llanos MJ, Guzmán Zamudio JL, Llanos de Los Reyes-García MJ. Significance of anaemia in the different stages of life. Enferm Glob. 2016; 43: 419-30.

16. McCann S, Amadó MP, Moore SE. The role of iron in brain development: A systematic review. Nutrients. 2020; 12: 2001.

17. Lozoff B, Georgieff MK. Iron deficiency and brain development. Semin Pediatr Neurol. 2006; 13(3): 15865.

18. Wiegersma AM, Dalman C, Lee BK, Karlsson H, Gardner RM. Association of prenatal maternal anemia with neurodevelopmental disorders. JAMA Psychiatry. 2019; 76(12): 1-12.

19. Anjum I, Jaffery SS, Fayyaz M, Samoo Z, Anjum S. The role of vitamin D in brain health: A mini literature review. Cureus. 2018; 10(7): e2960.

20. Voltas N, Canals J, Hernández-Martínez C, Serrat N, Basora J, Arija V. Effect of vitamin D status during pregnancy on infant neurodevelopment: The ECLIPSES study. Nutrients. 2020; 12: 3196.

21. Farghali M, Ruga S, Morsanuto V, Uberti F. Can brain health be supported by vitamin D-based supplements? A critical review. Brain Sci. 2020; 10: 0660.

22. Li B, Xu Y, Zhang X, Zhang L, Wu Y, Wang X, et al. The effect of vitamin D supplementation in treatment of children with autism spectrum disorder: a systematic review and meta-analysis of randomized controlled trials. Nutr Neurosci. 2020; 1-11.

23. Shunova A, Böckmann KA, Minarski M, Franz AR, Wiechers C, Poets CF, et al. Choline content of term and preterm infant formulae compared to expressed breast milk - How do we justify the discrepancies? Nutrients. 2020; 12: 3815.

24. Derbyshire E, Obeid R. Choline, neurological development and brain function: A systematic review focusing on the 1000 days. Nutrients. 2020; 12: 1731.

25. Merz EC, Monk C, Bansal R, Sawardekar S, Lee S, Feng $\mathrm{T}$, et al. Neonatal brain metabolite concentrations: Associations with age, sex, and developmental outcomes. PLoS ONE. 2020; 15(12): e0243255.
26. Wallace TC, Blusztajn JK, Caudill MA, Klatt KC, Natker E, Zeisel SH, et al. Choline: The underconsumed and underappreciated essential nutrient. Nutr Today. 2018; 53(6): 240-53.

27. Lauritzen L, Brambilla P, Mazzocchi A, Harsløf LBS, Ciappolino V, Agostoni C. DHA effects in brain development and function. Nutrients. 2016; 8: 6.

28. Meldrum S, Simmer K. Docosahexaenoic acid and neurodevelopmental outcomes of term infants. Ann Nutr Metab. 2016; 69(suppl 1): 23-8.

29. Calder PC. Docosahexaenoic acid. Ann Nutr Metab. 2016; 69(suppl 1): 8-21.

30. DiNicolantonio JJ, O'Keefe JH. The importance of marine omega-3s for brain development and the prevention and treatment of behavior, mood, and other brain disorders. Nutrients. 2020; 12: 2333. 